\title{
RELATIVE AMPLITUDES OF $P$ AND $S$ WAVES AS A MANTLE RECONNAISSANCE TOOL
}

\author{
By John R. McGinley, JR.* and Don L. Anderson
}

\section{ABSTRACT}

The unified magnitude, the ratio of the amiplitudes of $S$ to $P$ waves, and traveltime residuals were compiled from published data for the five Seismological Observatories, TFO, UBO, BMO, WMO and $C B O$. Using one of the stations as a reference, a relative measure of the above quantities was calculated for each of the other stations for each of a number of earthquakes. The stations in the Basin and Range Province are consistent with a markedly higher attentuation of $P$ waves and a high attenuation of $S$ relative to $P$ when compared to the other stations. This latter observation indicates a high Poisson's ratio in the mantle under the Basin and Range. The delay times to these stations are also consistent with the high Poisson's ratio and with a low-velocity upper mantle. The ratio of the amplitudes of longperiod $S$ waves to short-period $P$ waves varies by a factor of 4 among these stations.

$B M O$, in eastern Oregon, has a high $S / P$ amplitude ratio compared to other stations and a travel-time residual that is comparable to the observatories in the midcontinent. This may be another example of a seismic "window" into the upper mantle that is generated by underthrusting of the oceanic lithosphere.

\section{INTRODUCTION}

Travel-time residuals or $P$-delays are an important source of information regarding local or regional differences in the seismic properties of the crust and upper mantle. These have been shown to correlate well with other information, such as gravity anomalies (Press and Biehler, 1964). Amplitudes of seismic waves are also a useful measure of the properties of the crust and upper mantle. The attenuation of seismic energy is extremely sensitive to temperature and to the presence or absence of partial melting. Amplitudes of seismic waves also depend on the details of the velocity variation, both vertically and horizontally, and the radiation pattern of the source. We have attempted to suppress these effects by performing a statistical study of various amplitude ratios. Since we used published data rather than original seismograms this must be considered a pilot study of amplitude rations, but the results indicate that the amplitude ratio method is a powerful reconnaissance method for mapping anomalies in the upper mantle.

\section{DATA}

The principal source for the data used was "The Registration of Earthquakes at Blue Mountains Seismological Observatory (BMO), Cumberland Plateau Seismological Observatory (CPO), Tonto Forest Seismological Observatory (TFO), Uinta Basin Seismological Observatory (UBO), and Wichita Mountain Seismological Observatory (WMO)" [Teledyne Industries, 1966a]. The location of the observatories is given in Figure 1. The data used here are from either the short-period instruments which peak at about .35 sec or from the long-period instruments which peak at about 30 sec. Some data were taken from the "Seismological Bulletin Long-Range Measure-

\footnotetext{
* Now at Esso Production Research Co., Houston, Texas.
} 
ments Program" [Teledyne Industries, 1966b] for stations at Kanab Utah (KU); Mina, Nevada (MN); Jasper, Alberta (JP); and Prince George, British Columbia (PG). The location of the stations is shown in Figure 2. The instruments are essentially the same as for the observatories. Details can be found in the bulletins.

Three quantities were calculated:

(a) the ratio of $S$-amplitude to $P$-amplitude at each station relative to the same ratio at $\mathrm{UBO}$;

(b) the ratio of the $P$-amplitude at each station relative to the $P$-amplitude at UBO;

(c) the travel-time residual at each station relative to the travel-time residual at UBO.

\begin{tabular}{|c|c|c|c|c|c|}
\hline Observatory: & BMSO & CPSO & TFSO & UBSO & WMSO \\
\hline $\begin{array}{l}\text { Observatory iden- } \\
\text { tification on film } \\
\text { seismographs }\end{array}$ & BMO & CPO & TFO & UBO & WMO \\
\hline Location: & $\begin{array}{l}\text { Baker, } \\
\text { Oregon }\end{array}$ & $\begin{array}{l}\text { McMinn- } \\
\text { ville, } \\
\text { Tennessee }\end{array}$ & $\begin{array}{l}\text { Payson, } \\
\text { Arizona }\end{array}$ & $\begin{array}{l}\text { Vernal, } \\
\text { Utah }\end{array}$ & $\begin{array}{l}\text { Ft. Sill, } \\
\text { Oklahoma }\end{array}$ \\
\hline $\begin{array}{l}\text { Geographic } \\
\text { coordinates: }\end{array}$ & $\begin{array}{l}44^{\circ} 50^{\prime} \\
56^{\prime \prime} \mathrm{N}- \\
117^{\circ} 18 \\
20^{\prime \prime} \mathrm{W}\end{array}$ & $\begin{array}{l}35^{\circ} 35^{\prime} \\
41^{\prime \prime} \mathrm{N}- \\
85^{\circ} 34^{\prime} \\
13^{\prime \prime} \mathrm{W}\end{array}$ & $\begin{array}{l}34^{\circ} 16^{\prime} \\
04^{\prime \prime} \mathrm{N}- \\
111^{\circ} 16^{\prime} \\
13^{\prime \prime} \mathrm{W}\end{array}$ & $\begin{array}{l}40^{\circ} 19^{\prime} \\
18^{\prime \prime} \mathrm{N}- \\
109^{\circ} 34^{\prime} \\
07^{\prime \prime} \mathrm{W}\end{array}$ & $\begin{array}{l}34^{\circ} 43^{\prime} \\
05^{\prime \prime} \mathrm{N}- \\
98^{\circ} 35^{\prime} \\
21^{\prime \prime} \mathrm{W}\end{array}$ \\
\hline $\begin{array}{l}\text { Elevation } \\
\text { (meters above } \\
\text { mean sea level): }\end{array}$ & $\begin{array}{l}1189 \\
(3900 \mathrm{ft})\end{array}$ & $\begin{array}{l}574 \\
(1883 \mathrm{ft})\end{array}$ & $\begin{array}{l}1492 \\
(4894 \mathrm{ft})\end{array}$ & $\begin{array}{l}1600 \\
(5248 \mathrm{ft})\end{array}$ & $\begin{array}{l}505 \\
(1658 \mathrm{ft})\end{array}$ \\
\hline $\begin{array}{c}\text { Geology of } \\
\text { bedrock: }\end{array}$ & Granite & $\begin{array}{l}\text { Sand stone/ } \\
\text { limestone }\end{array}$ & Granite & Sandstone & $\begin{array}{l}\text { Granophyre } \\
\text { (porphyritic) }\end{array}$ \\
\hline
\end{tabular}

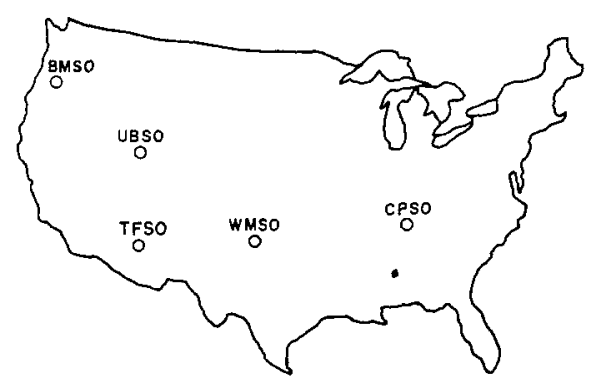

Fic. 1. Location of observatories (from the Registration of Earthquakes, Teledyne Industries, 1966a).

$S / P$ Ratio for $T F O, W M O, C P O, B M O$. Calculation of the $S / P$ ratio was restricted to earthquakes for which the station to epicenter azimuth differed by less than $11^{\circ}$ from the UBO to epicenter azimuth, and neither the station nor UBO was greater than $96^{\circ}$ from the epicenter. These restrictions were for the purpose of suppressing the effects of source radiation patterns and core diffraction. Data were taken from the above station bulletins for the period May through August, 1966. The amplitudes given in the bulletins are corrected for instrument response. The amplitudes of the $P$ and $S$ arrivals were normalized (i.e., divided) by the dominant period of the pulse. The $P$-amplitude was always taken from a short-period instrument and the 
$S$-amplitude from a long-period instrument. The $P$ pulses used were usually near 1 second in period ranging from about .5 to 2 seconds while the $S$ pulses used were generally near 20 seconds in period ranging from about 15 to 30 seconds. No correction was made for the differences in distance of the stations from the epicenter. The largest possible difference in distance (using UBO as a reference) is about $20^{\circ}$ for CPO.

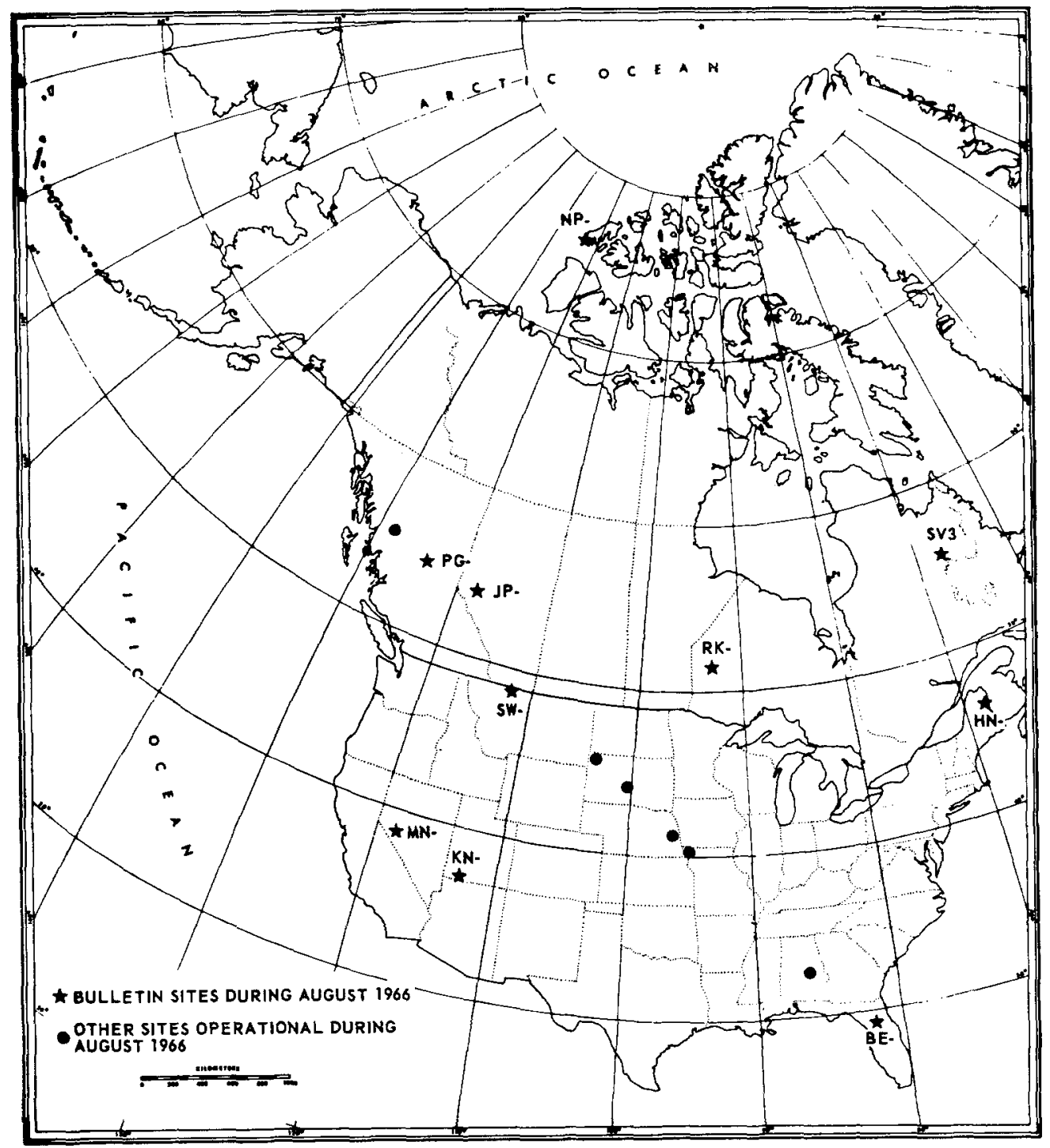

FIG. 2. Location of LRSM sites (from the Seismological Bulletin Long-Range Seismic Measurements, Teledyne Industries, 1966b).

The restriction on azimuth difference and the restriction that the data at the station and at UBO come from the same earthquake should tend to remove radiation pattern and source region effects. The ratio of normalized $S$ to normalized $P$ for the station was divided by the ratio of normalized $S$ to normalized $P$ for UBO. These twice normalized amplitude ratios will be called the " $S / P$ ratio" for the station. Data were not available or did not meet the restrictions for all stations from every earth- 
quake, so the results for each station are based on somewhat different samples of earthquakes.

$S / P$ Ratio for $K N, M N, J P, P G$. Calculation of the $S / P$ ratio for these stations was as above except the azimuth and distance restrictions were not applied. Data was taken from Seismological Bulletin, Long-Range Seismic Measurements Program for May through August, 1966.

P-ratio for TFO, WMO, CPO, BMO. In "The Registration of Earthquakes" the unified magnitude is given for all suitable $P$ arrivals. Corrections for hypocentral depth and distance to the earthquake are applied. No station correction is made. For each earthquake the magnitude at UBO was subtracted from the magnitude at each station giving the magnitude difference relative to UBO. The $\log _{10}$ of the mag-

TABLE 1

Observed $P$-ratios, $S / P$-ratios, and $P$-Residuals with "Standard Deviation Factor" and "STandard Error Factor" all Referenced to UBO

\begin{tabular}{|c|c|c|c|c|}
\hline Station & P-ratio & $\begin{array}{c}\text { "Standard Deviation } \\
\text { Factor" }\end{array}$ & $\begin{array}{l}\text { "Standard Error } \\
\text { Factor" }\end{array}$ & $\begin{array}{l}\text { Number of } \\
\text { Observations }\end{array}$ \\
\hline TFO & .6 & $\stackrel{\times}{\div} 2.5$ & $\underset{\div}{x_{1}} 1.1$ & 61 \\
\hline WMO & .9 & 2.5 & 1.1 & 56 \\
\hline $\mathrm{CPO}$ & 1.6 & 2.4 & 1.1 & 46 \\
\hline \multirow[t]{2}{*}{$\mathrm{BMO}$} & .6 & 2.2 & 1.1 & 58 \\
\hline & $S / P$-ratio & & & \\
\hline TFO & 1.2 & $\stackrel{\times 2.6}{\doteqdot}$ & $\stackrel{x_{1}}{-1.2}$ & 34 \\
\hline WMO & 2.3 & 3.2 & 1.3 & 24 \\
\hline $\mathrm{CPO}$ & 1.8 & 2.0 & 1.2 & 10 \\
\hline BMO & 4.0 & 4.1 & 1.4 & 21 \\
\hline $\mathrm{KN}$ & 1.6 & 2.6 & 1.3 & 13 \\
\hline $\mathrm{MN}$ & 2.0 & 3.2 & 1.5 & 7 \\
\hline JP & 1.8 & 1.8 & 1.4 & 8 \\
\hline \multirow[t]{2}{*}{$P G$} & 2.7 & 2.4 & 1.2 & 15 \\
\hline & $P$-residual (seconds) & Standard Deviation & Standard Error & \\
\hline TFO & +.4 & \pm .8 & \pm .1 & 55 \\
\hline WMO & -.6 & 1.3 & .2 & 40 \\
\hline $\mathrm{CPO}$ & -.8 & 1.3 & .2 & 37 \\
\hline $\mathrm{BMO}$ & -.7 & 1.0 & .1 & 51 \\
\hline
\end{tabular}

nitude difference gives the ratio of the $P$-amplitude at the station to the $P$-amplitude at UBO (the amplitude ratio being implicitly corrected for the same effects as the magnitude) and will be called the "P-ratio" for the station. No correction was made for radiation pattern. Data was taken from about the first half of August, 1966.

$P$-residual for $T F O, W M O, C P O, B M O$. The travel time residual with reference to the 1958 Jeffreys-Bullen Travel Time Tables is also given in "The Registration of Earthquakes". This travel time residual for $P$ arrivals was corrected according to the "Average Surface Focus Travel Time Curve" given by Carder et al (1966). For each earthquake the corrected $P$ travel time residual at UBO was subtracted from the corrected $P$ travel time residual at the station to give the " $P$-residual" for the station. The data used were from the same time period as for the $P$-ratio.

\section{Results AND Discusston}

The results and some statistical measures are given in Table 1. A summary of the results used in the discussion of $Q$ is given in Table 2 . The $P$-residuals were assumed 
normally distributed. For the observations which are ratios a logarithmic normal distribution was assumed (i.e., the logarithms of the measurements are assumed normally distributed). The statistical measures identified as "standard deviation factor" and "standard error factor" are the antilogs of the standard deviation of the logarithms and the standard error of the mean of the logarithms. They are intended to be used as multiplicative factors with an intuitive interpretation analogous to the standard deviation and standard error.*

Figures 3 through 6 show all of the data for selected stations. The indicated quantity is plotted versus epicentral distance from UBO and histograms are constructed for the same data. Qualitatively the histograms leave some doubt about the assumption of a normal distribution. Observations indicated by an arrow were excluded in calculating the results given in Table 1.

The $S / P$-ratio and $P$-ratio can be interpreted as a very rough measure of upper mantle absorption at each station relative to upper mantle absorption at UBO-higher ratios corresponding to lower absorption. The $P$-residuals are independent, but it is reasonable to expect more positive $P$-residuals to correlate with high absorption. Complications in this obviously oversimplified interpretation are discussed briefly

TABLE 2

SUMMary of $P$-RATIOS AND $S / P$-RAtios

\begin{tabular}{|c|c|c|c|}
\hline Station & $\begin{array}{c}P \text {-ratio } \\
P_{\mathrm{STA}} / P_{\text {}} \text { ठBO }\end{array}$ & $\begin{array}{c}S / P \text {-ratio } \\
(S / P) \mathrm{STA} /(S / P)_{\mathrm{UBO}}\end{array}$ & $S$ Sta $/ S$ u bo $\neq$ \\
\hline TFO & .6 & 1.2 & .7 \\
\hline WMO & .9 & 2.3 & 2.0 \\
\hline CPO & 1.6 & 1.8 & 2.9 \\
\hline BMO & .6 & 4.0 & 2.4 \\
\hline
\end{tabular}

$\ddagger$ Derived by multiplying the $S / P$-ratio by the $P$-ratio.

below, but neglecting these for the moment, $\mathrm{UBO}$ and TFO are fairly well distinguished as the most absorptive stations.

Under many assumptions a quantitative estimate of the relative absorption at the different stations can be made. Let all the absorption for a given station occur in a single layer with quality factor $Q^{i}$, thickness $X$, and velocity $v^{i}$ for waves of period $T^{i}$, and let crustal structure and site effects be included in a "crustal factor" $A_{c}{ }^{i}-$ where $i=p$ for compressional waves, $s$ for shear waves. Then the amplitude observed at station 1 is

$$
A_{1}^{i}=A_{0}{ }^{i} A_{c}^{i} \exp \left(-k_{1}^{i} X_{1}\right)
$$

where $A_{0}{ }^{i}$ is the amplitude at the source and

$$
k_{1}^{i}=\frac{\pi}{Q^{i} v^{i} T^{i}} .
$$

*For example the P-ratio for TFO is .6 with a "standard deviation factor" of 2.6, and this is taken to imply that about $67 \%$ of the measurements lie between $0.6 \times 2.6=1.6$ and $0.6 \div 2.6=$ 0.2. The "standard error factor" of $\mathbf{1 . 1}$ for this measurement implies that the true P-ratio is more likely to lie between $0.6 \times 1.1=0.7$ and $0.6 \div 1.1=0.5$ than not. 
Straightforward algebra gives

$$
R_{1} \equiv A_{1}^{p} / A_{2}^{p}=A_{1 c}^{p} / A_{2 c}^{p} \exp \left[-\left(k_{1}^{p}-k_{2}^{p}\right) X_{1}\right]
$$

for the amplitude of $P$ waves at station 1 relative to station 2 . And

$$
R_{2} \equiv \frac{A_{1}^{p} / A_{1}{ }^{s}}{A_{2}^{p} / A_{2}{ }^{s}}=\frac{A_{1 c}^{p} / A_{1 c}^{s}}{A_{2 c}^{p} / A_{2 c}^{s}} \exp \left\{-\left[\left(k_{1}^{p}-k_{2}^{p}\right)-\left(k_{1}^{s}-k_{2}^{s}\right)\right] X_{1}\right\}
$$

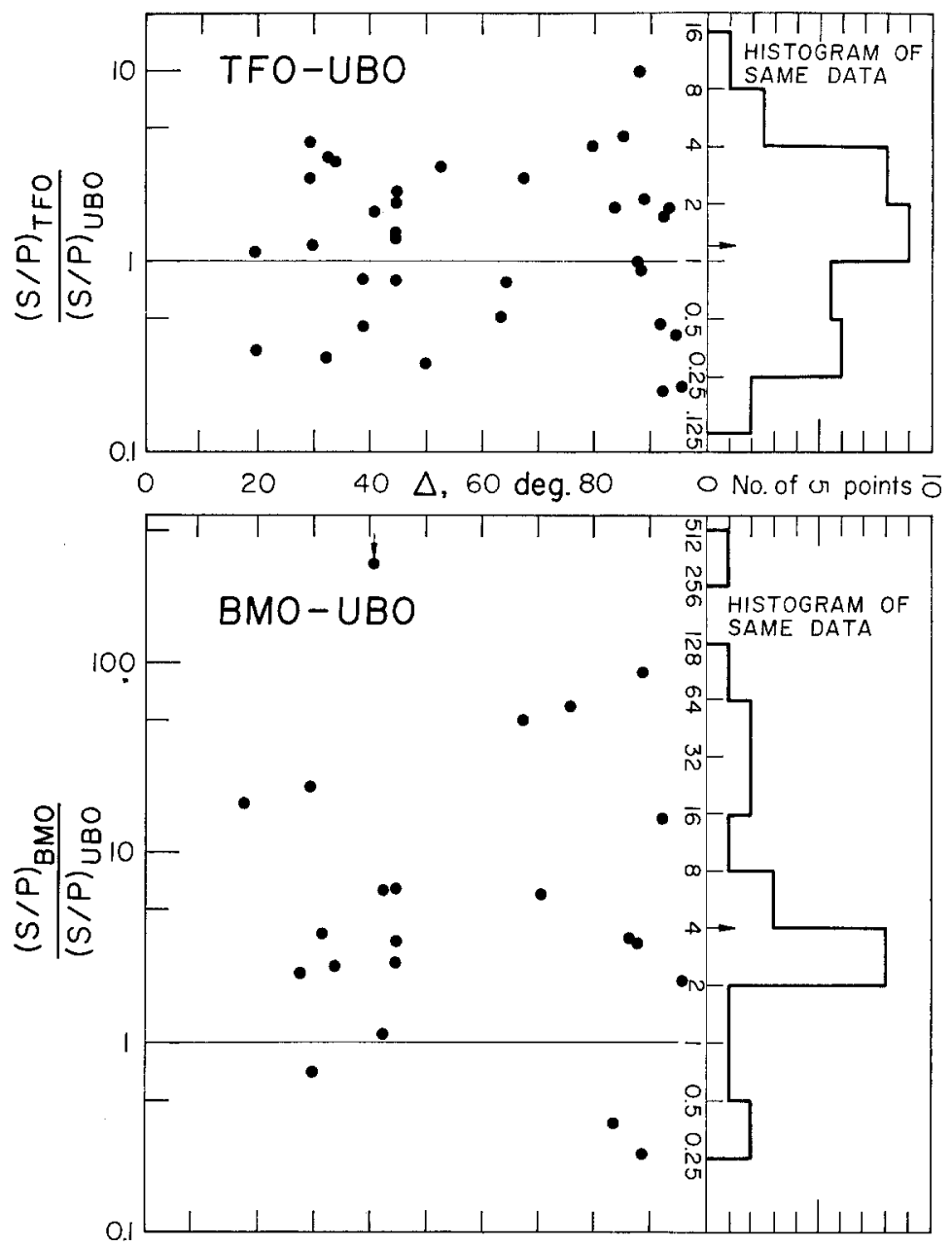

Frg. 3. $S / P$-ratio for TFO versus distance to UBO and for BMO versus distance to UBO.

for the $P / S$ ratio at station 1 relative to station 2 . Assuming that the crustal factors are the same for all stations

$$
Q_{1}^{p}=\frac{\pi}{v^{p} T^{p}} \frac{1}{\left(k_{2}^{p}-\frac{\ln R_{1}}{X_{1}}\right)}
$$


Relative ayiplitudes of $P$ and $S$ Waves as Mantle ReCONNaissance tool 1195 and

$$
Q_{1}^{s}=\frac{\pi}{v^{s} T^{s}} \frac{1}{\left(k_{1}^{p}-{k_{2}}^{p}+k_{2}^{s}+\frac{\ln R_{2}}{X_{1}}\right)}
$$

If the $Q_{2}{ }^{i}$ are known or assumed the $Q_{1}{ }^{i}$ can be calculated. The results of such calculations are given in Table $3 . Q^{i}$ values were assumed for WMO. The results for $Q_{2}{ }^{i}=$ $\infty$ at WMO would be upper bounds on $Q$ at the other stations if the assumptions made

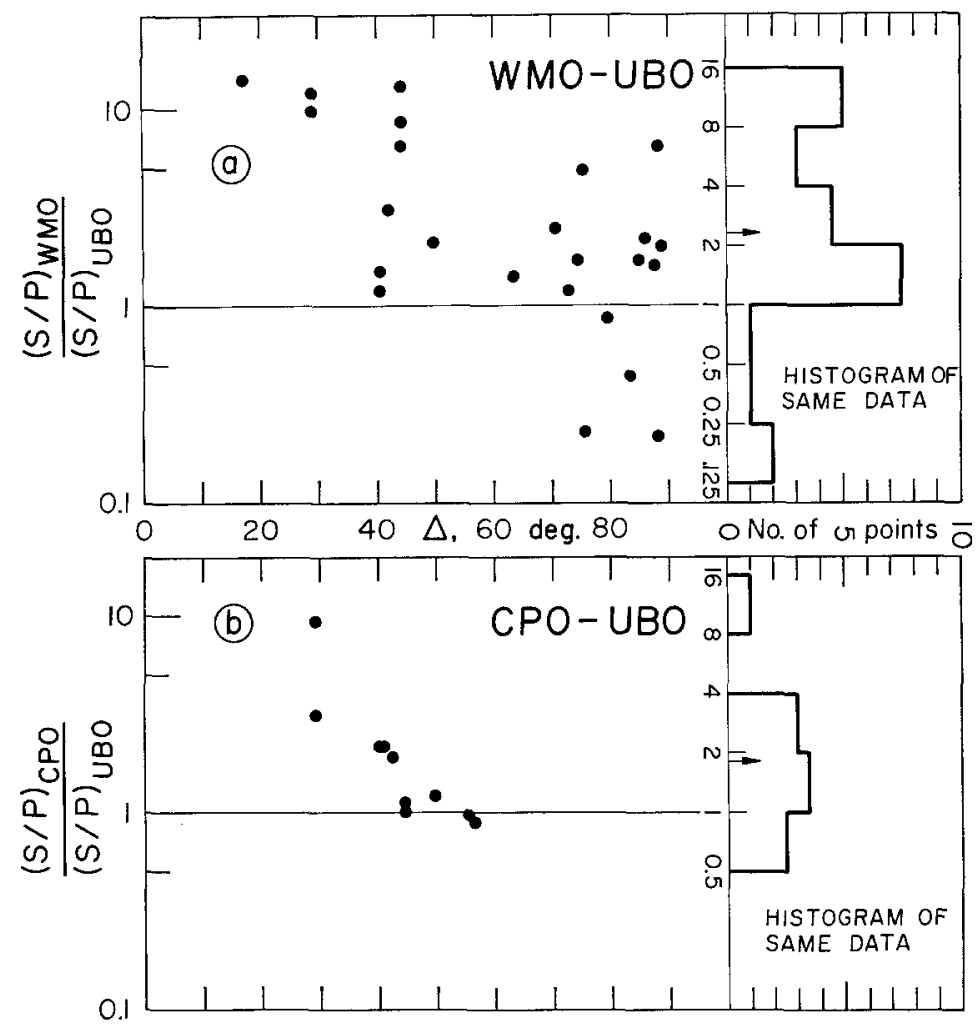

Frg. 4. $S / P$-ratio for WMO versus distance to UBO and for CPO versus distance to UBO.

were correct. Locations in Table 3 which are filled with a dash gave negative $Q$ values which shows that the assumed conditions are incompatible with the data for these cases.

The ratio $Q^{p} / Q^{s}$ can be written

$$
\begin{aligned}
Q^{p} / Q^{s} & =\left(\frac{\alpha}{\beta}\right)^{2}\left[\frac{\mu^{*}}{k^{*}+4 \mu^{*} / 3}\right] \\
& =\frac{2(1-\sigma)}{1-2 \sigma}\left[\frac{\mu^{*}}{k^{*}+4 \mu^{*} / 3}\right]
\end{aligned}
$$

where $k^{*}$ and $\mu^{*}$ are the imaginary parts of the bulk and shear moduli, $\sigma$ is Poisson's ratio, and $\alpha$ and $\beta$ are the compressional and shear velocities. Clearly $Q^{p} / Q^{s} \rightarrow \infty$ 
as $\sigma \rightarrow \frac{1}{2}$. If all losses are in shear $k^{*}=0$ and $Q^{p} / Q^{s}=3(1-\sigma) / 2(1-2 \sigma)$. For $\sigma=\frac{1}{4}, Q^{p} / Q^{s}=2.25$ and for $\sigma=0.4, Q^{p} / Q^{s}=6$. A high ratio of $Q^{p}$ to $Q^{s}$ indicates a high value of Poisson's ratio. The derived values of $Q^{p}, Q^{s}$, and $Q^{p} / Q^{s}$ in Table 3 show either very low $Q$, very high $Q^{p} / Q^{s}$, or both. Increasing $X_{1}$ tends to increase the $Q$ estimates and decrease $Q^{p} / Q^{s}$, but the derived values in Table 3 are dominated by the $P$-ratio. Comparing any two stations with $P$ amplitude differences as large as the difference between TFO and WMO gives similar results. Jordan et al (1965) have

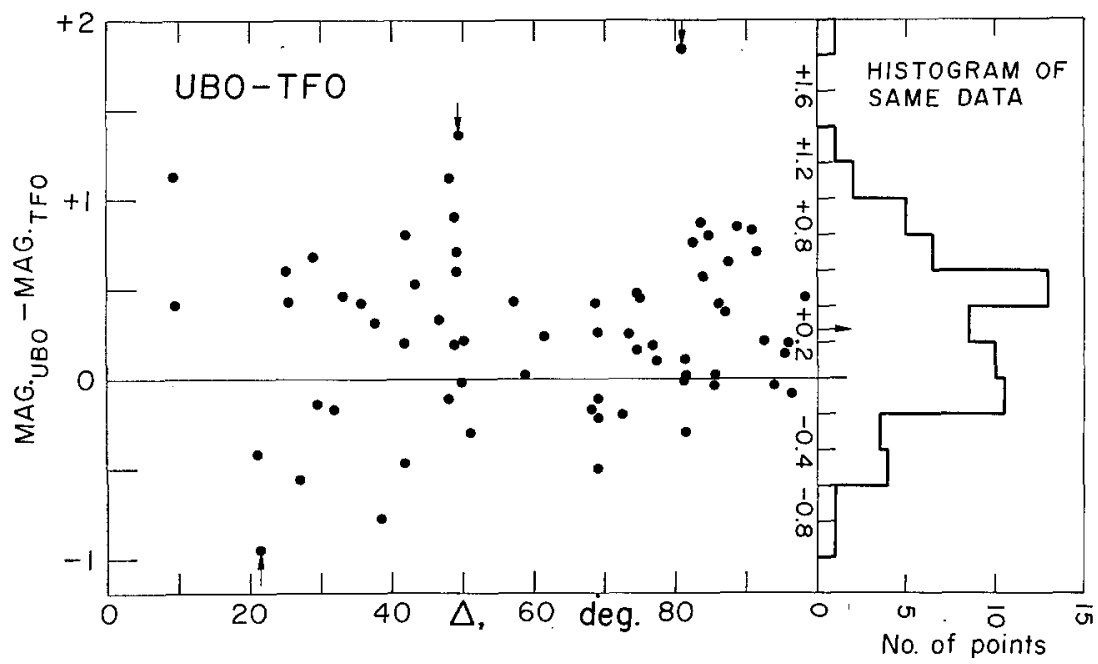

FIG. 5. Magnitude difference UBO-TFO versus distance to UBO.

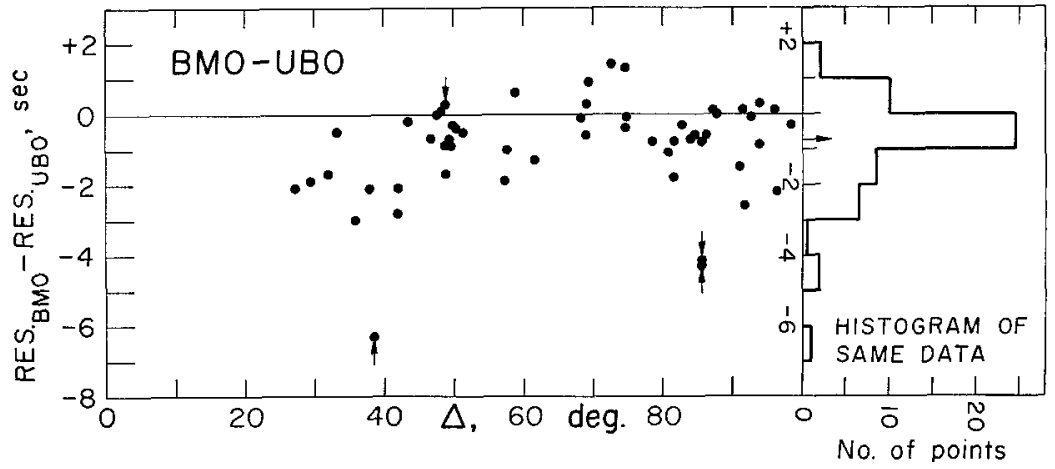

Frg. 6. P-residual to BMO less $P$-residual at UBO versus distance to UBO.

contoured amplitude patterns for $P$ waves of about 1 second period and have shown that $P$ amplitudes can vary within the limits in Table 2 due to local effects at the receiver and the source. Therefore the individual entries for relative $P$ amplitudes are liable to be controlled by the structure at the recording site. However, Jordan et al (1965) point out that there are indications of regional systematics with amplitudes lower in the western part of the United States than in the eastern part. It is difficult to associate a quantitative value with the difference, but a 3 to 2 ratio as shown for WMO and TFO in Table 2 appears reasonable. The results in Table 3 show that such an amplitude difference requires a very low $Q$ or high Poisson's ratio under the assumed conditions. Either result indieates an approach to high tempera- 
ture or fluid-like behavior. It should be noted that the lowest $Q$ values in a given column in Table 3 are determined essentially by the assumed values at WMO rather than by the station observations. There is also the possibility that regional structural differences determine regional $P$ amplitude differences so that the inference of low $Q$ or high Poisson's ratio is not definitive.

An estimate of the $S$-ratio, defined in a manner analogous to the $P$-ratio, can be derived by multiplying the $P$-ratio times the $S / P$-ratio. This has been done to give the $S$-ratio in the third column of Table 2 . It should be noted that the $S / P$-ratio and $P$-ratio were determined from different sets of data. Since the $S$-waves typically have about a 20 second period, the $S$-ratio should be much less sensitive to local structural variations than the $P$-ratio. On the basis of $S$-ratio relative to UBO the stations can be separated into two groups-UBO and TFO with an $S$-ratio of 1 or less, and WMO, CPO, and BMO with an S-ratio of 2 or greater. Using the same derivation as given for $Q_{1}{ }^{p}$ previously, but with $s$ substituted for $p$, the $Q^{s}$ at one station

TABLE 3

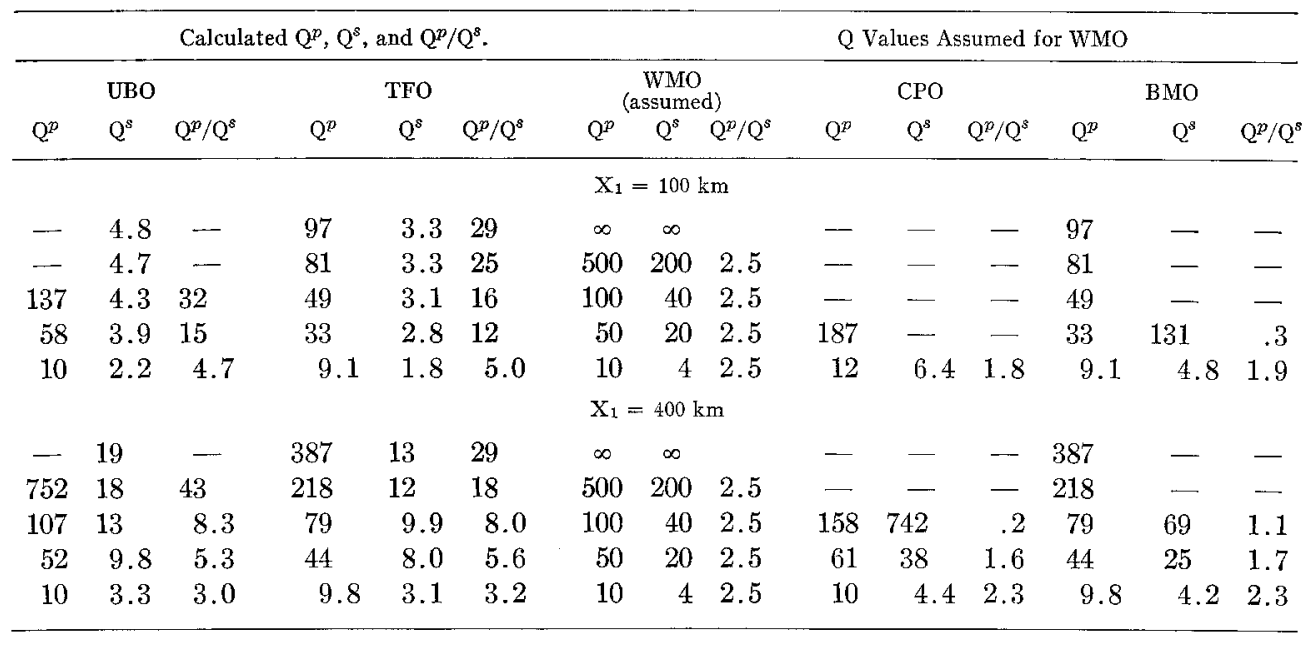

can be assumed and the $Q^{s}$ at other stations calculated. The results of such a calculation when $Q^{s}$ values were assumed at BMO are given in Table 5 . For $X_{1}=100 \mathrm{~km}$. The upper bounds of $Q^{s}$ at UBO and TFO are less than 50. Similar bounds result if WMO or CPO are used as a reference station. The thickness of the layer in which $Q$ differences are allowed is important in determining the bound as is shown by the increase in the upper bound at UBO and TFO when $X_{1}=400 \mathrm{~km}$. As in Table 3 the lowest $Q^{s}$ values in each column are determined essentially by the assumed values at BMO. If the assumptions in the calculations are correct, the inference is a fairly low $Q^{s}$ under TFO and UBO or substantial $Q^{s}$ differences through regions of at least several hundred kilometers extent.

An absolute $P$-residual was determined from the relative $P$-residuals in Table 1 by assuming that the correction curve of Carder et al (1966) to the Jeffreys-Bullen travel times has an average of -2.0 seconds. The resulting $P$-residuals, Table 4 , correlate with the $S$-ratios as expected if the $S$-ratios are due to regional differences in $Q^{s}$. UBO and TFO show a positive residual and WMO, CPO, and BMO show negative residuals. $P$-residuals given by Carder et al (1966), Cleary and Hales (1966), and Herrin et al (1968) are also listed in Table 4. The correlation of the S-ratios with the 
other determinations of station residuals given in Table 4 is not perfect, but only the determination of Carder et al (1966) for UBO is in substantial disagreement.

Introducing an $S$-delay, as would be implied by relatively long transit times for $S$ waves in an absorbing layer, tends to reduce the high $Q^{p} / Q^{s}$ ratios in Table 3 . However, this is equivalent to assuming a high Poisson's ratio. A cursory examination of $S$ arrival times reported in the Registration of Earthquakes does not exclude the possibility of large relative $S$-delay. The study of Doyle and Hales (1966) implies $S$-delays of 3-4 seconds for TFO and UBO relative to BMO. Their results can be interpreted, Hales and Doyle (1967), to give a Poisson's ratio of about .325 for $X=100$

TABLE 4

Comparison of Station Residuals

\begin{tabular}{lcccc}
\hline Station & This Report & Carder, et al & Cleary and Hales & Herrin \\
\hline UBO & +.4 & -.3 & +.0 & +.10 \\
TFO & +.7 & +1.0 & +.7 & +.64 \\
WMO & -.3 & -.1 & -.9 & -.70 \\
CPO & -.5 & -.5 & $-\mathbf{1 . 1}$ & -.73 \\
BMO & -.4 & -.7 & -.2 & -.41 \\
\hline
\end{tabular}

TABLE 5

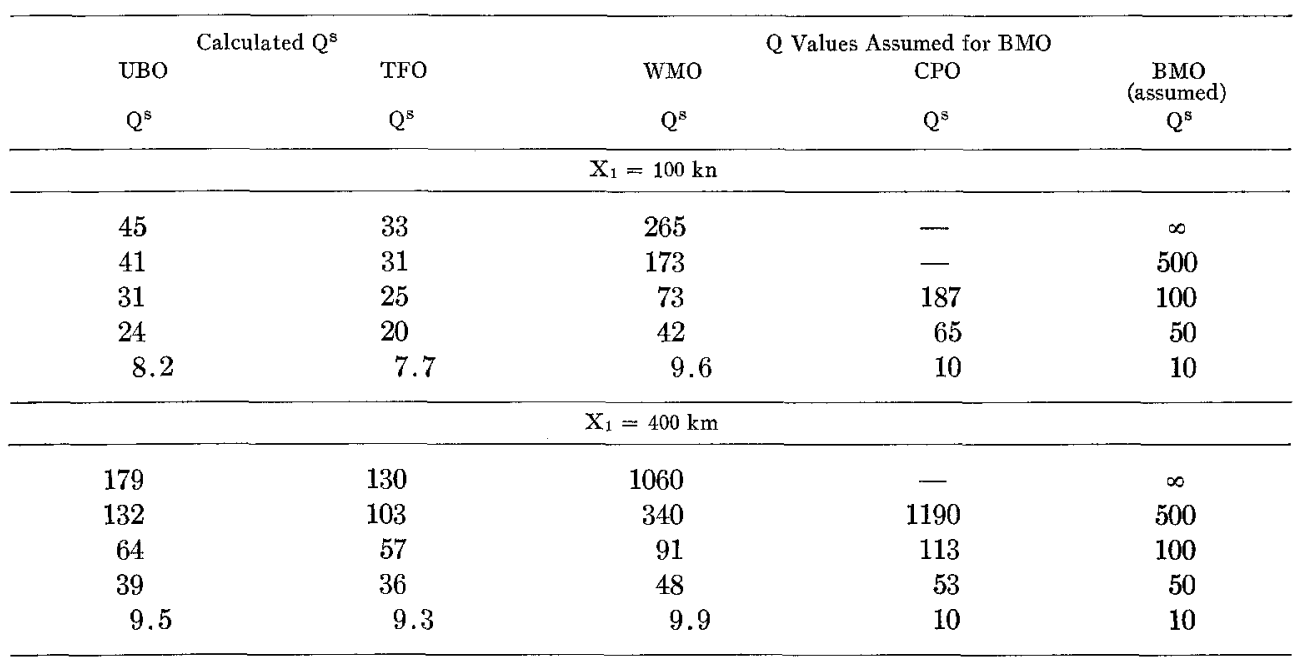

$\mathrm{km}$ or .275 for $X=400 \mathrm{~km}$ in the region of UBO and TFO. Such changes in S-delay or Poisson's ratio do not change the basic pattern of low $Q$ and high $Q^{p} / Q^{s}$ in Table 3.

No attempt is made at a complete listing of factors which may influence the data, but the following illustrate the important difficulties. Since the $S / P$-ratios are not corrected for distance there could be an important distance effect. Figure 4 supports the idea that the ratios for WMO and CPO decrease with average distance from the epicenter. Bolt and Nuttli's (1966) study indicates some large azimuthal effects. Misidentification of phases and source radiation patterns could bias the data. Although the statistical measures indicate an adequate sample size for the stations represented in Table 2, the assumptions underlying these estimates may not be satisfied. A statistical study of magnitudes by Swanson (1966) based on a much larger sample 
size leads to $P$-ratios within .1 of those in Table 2 except for BMO. Swanson's results give $P_{\text {вмо }} / P_{\text {Uво }} \approx 1.1$.

\section{CONCLUSION}

The results of this study are consistent with either a very low $Q$ upper mantle or a very high Poisson's ratio in the Basin and Range Province or both. The shear wave "transparency" of the upper mantle in Oregon was somewhat surprising. This may be another region where a high $Q$ lithosphere is being thrust into a normally low $Q$ upper mantle (Oliver and Isacks, 1967).

The interpretational difficulties inherent in a study of this type are fairly obvious. Although large amounts of data can be handled in a relatively short time and statistical analysis may be made of the results this does not compensate for a detailed study of the individual records. Misidentification of phases, azimuth effects, source radiation patterns and geometrical effects may all bias the data and affect some of the conclusions. It seems clear, however, that the ratio of long-period shear wave energy to short-period $P$ wave energy is highly variable. A more detailed study, including spectral techniques, is clearly warranted. We believe, however, that we have established the $S / P$ ratio as an important parameter in studies of the regional variation of the properties of the crust and upper mantle.

Our interpretation of the amplitude anomalies in terms of attenuation and Poisson's ratio in the upper mantle is only one possibility. Body-wave amplitudes are also affected by crustal structure and we do not rule out the possibility of this effect. However, the range of the $P$-residuals indicates that all of the differences, at least in the travel-time data, cannot be attributed to the crust. At BMO the low $P$ amplitudes and the high $S$ amplitudes and the normal $P$ residual suggest that crustal effects may be important at this station.

\section{Acknowledgments}

This research was supported by the Air Force Office of Scientific Research, United States Air Force, under AFOSR contract AF-49(638)-1337. We are grateful to David Hill for critically reading the manuscript.

\section{REFERENCES}

Bolt, B. A. and O.W. Nuttli (1966). P-Wave residuals as a function of azimuth, J. Geophys. Res. $71,5977-5985$.

Carder, D. S., D. W. Gordon and J. N. Jordan (1966). Analysis of surface-foci travel times, Bull. Seism. Soc. Am. 56, 815-840.

Cleary, J. and A. L. Hales (1966). An analysis of the travel times of $P$-waves to North American stations, in the distance range $32^{\circ}$ to $100^{\circ}$, Bull. Seism. Soc. Am. 56, 467-489.

Doyle, H. A. and A. L. Hales (1966). An analysis of the travel times of $S$-waves to North American stations, in the distance range $28^{\circ}$ to $82^{\circ}$, Bull. Seism. Soc. Am. 57, 761-771.

Hales, A. L. and H. A. Doyle, (1967). $P$ and $S$ travel time anomalies and their interpretation, manuscript.

Herrin, E., J. Taggert and A. Hales (1968). Regional variations in $P$ travel times, manuscript.

Jordan, J., R. Black and C. C. Bates (1965). Patterns of maximum amplitudes of $P_{n}$ and $P$ waves over regional and continental areas, Bull. Seism. Soc. Am. 55, 693-720.

Oliver, J. and B. Isacks (1967). Deep earthquake zones, anomalous structures in the upper mantle, and the lithosphere, J. Geophys. Res. 72, 4259.

Press, F. and S. Biehler (1964). Inferences on crustal velocities and densities from $P$ wave delays and gravity anomalies, $J$. Geophys. Res. 69, 2979-2995.

Swanson, J. G. (1966). Magnitude studies conducted under Projects VT/5054 and VT/5055, 
Technical Report No. 66-73, sponsored by ARPA, Nuclear Test Detection Office, ARPA Order No. 624, Prepared by Teledyne Industries, Geotech Division, 34 pp.

Teledyne Industries, Geotech Division (1966a). The registration of earthquakes 5, Nos, 5, 6, 7, 8. Prepared for the Air Force Technical Application Center, Washington, D. C., under ARPA Project vela UNIFORM.

Teledyne Industries, Geotech Division (1966b). Long-range seismie measurements program, Seismological Bulletin 53, 54, 55, 56.

Seismological Laboratory

California Institute of Technology

Pasadena, California

Division of Geological Sciences Contribucion No: 1574.

Manuscript received September 26, 1968. 